\section{TAILS ${ }^{1}$}

W HAT are tails? The question seems an almost trivial one in its simplicity. Dictionaries tell us that the word "tail" denotes certain parts of animals, and also the hindermost or lowermost portion of anything. We speak habitually of the "tail of a coat," the "tail end of a crowd," the "tail of a kite," and of "pig-tails," as well as "tails of pigs." Evidently all these appellations are in use from the perception of more or less close analogies between the various things thus spoken of and certain things which every one who speaks English must call a tail-something which is unmistakably, truly, and properly a tail.

Such a thing, for example, is the tail of a cat or of a dog. Let us, then, examine such an object and see what a typical tail is, and afterwards compare therewith other structures more or less closely or remotely resembling it.

But in order to understand that part of a cat which is called its "tail," we must understand those other parts which are not its tail, since we can never know any one thing whatever except by knowing other things from which such one thing is distinguished. We could not know "white," if everything that we saw was always of that colour.

The frame of a cat consists of a head, a trunk, limbs, and a tail.

Let us first look at its trunk. It consists of a solid fleshy wall (partly strengthened by bones--the ribs, breastbone and backbone) containing a cavity within this cavity within the trunk is called the body-cavity. Inside this body-cavity are a variety of parts (viscera), such as the heart and its great blood-vessels, the liver, \&c., and the cavity is traversed by a long, much-coiled tube called the alimentary canal, i.e., swallow, stomach, intestines, \&c.). Passing along the upper or dorsal side of the body is the backbone just mentioned. This consists of a complex chain of neatly articulated bones, each of which is called a vertebra, and the whole series of such bones form the vertebral column, spine, or spinal column, which are other names for the backbone. Now observe: Each vertebra of the trunk is in the form of an irregular ring. Therefore, as these rings come naturally in a series one behind the other, they together form a canal. This canal is called the neural canal, because it contains the central part of the nervous system, or neural axis, also improperly called the spinal marrow.

Thus, altogether, the cat's trunk consists of a solid case containing a body-cavity (within which lie the viscera), while the dorsal region of the case is traversed by the backbone or vertebral column, forming a canal along which runs the spinal marrow.

The neck is but the anterior prolongation of the trunk.

The cat's head is much more bony in proportion than is the trunk, and consists partly of a solid box, which holds the brain and shelters the ears and eyes and partly of a face and jaws, which latter bound the mouth. The brain case has a large hole behind, which matches with those which exist in each trunk vertebra, and through this hole the neural canal is continued on into the hollow of the skull, which is its expanded front end. Thus, altogether, the cat's head is in certain respects like its trunk. It is traversed by the alimentary tube, which opens at the mouth, and it has its dorsal part formed by the much-expanded neural canal (the skull-cavity) which contains the brain, or much-expanded anterior end of the neural axis.

The cat's limbs are very different in structure from the head and trunk. No body-cavity is contained in them, nor does the body-cavity of the trunk extend into any limb, nor again is any limb traversed by any part of the alimentary canal. Each limb has a solid bony support within it, but this support (the skeleton of each limb) is

A Davis lecture recently delivered at the Zoological Gardens by Prof. St. Gcorge Mivart, F.R.S., V.P.Z.S no part of the vertebral column, nor is it composed of any sort of vertebræ, but consists of a definite number of longer or shorter bones which are related to the support of the body or to its progression in walking, running, jumping, \&c. These limb-bones do not contain any canal (as the backbone does), nor do they shelter any continuation sideways from the central part of the nervous system.

We now come to the tail, and if we examine it, we shall see that, to a certain extent, it partakes of the natures both of the trunk and of the limbs. It is like the limbs in that it is solid, that it contains no body-cavity, and is not traversed by the alimentary canal.

It is like the trunk in that it contains a prolongation of the vertebral column, and of the neural canal. In the head, we saw that the neural canal expanded, it receives its anterior enlarged termination-the brain. In the tail the neural canal contracts, and soon ceases, as it incloses the progressively diminishing posterior end of the neural axis - the termination backwards of the spinal marrow.

Let us examine the bones which form the cat's tail a little closely. They are about a score in number. The first seven or eight are all in the form of rings of bone, but behind these the vertebræ become merely more or less elongated solid bony cylinders, which get gradually smaller till they become mere rudiments of vertebræ. Beneath the vertebræ run blood-vessels, and on all sides are muscles which serve to bend the tail in all directions.

Such is the structure of the tail in this animal, its use (or "function") is not very important. Cats can live very well without their tails, and the well-known Isle of Man variety-the Manx cat-has scarcely more visible tail than we have ourselves. Yet the cat's tail no doubt aids to a certain extent in maintaining the balance of the body in the animal's various motions, and especially perhaps in climbing. Everybody has noticed the lateral undulations of the end of the tail of a cat which is watching a mouse, and it is curious to note how the wagging of the tail in the cat and the dog respectively, accompany very different emotions.

The gesture language of these two animals as expressec. by the motion of their tails, and, indeed, by various other motions, is exceedingly different.

The structural characters which have been noticed concerning the cat's tail are substantially similar in all other beasts. In all, the tail is formed by a prolongation of the back bone (with more or less of neural canal), but has no body-cavity, and is not traversed by the alimentary canal.

But, although the essential structure in all beasts is similar, there are certain subordinate differences which merit our attention in the form of the tail in different beasts.

Dogs and cats belong to a great group of flesh-eating beasts, called, from their predominant mode of feeding, "carnivora." Bears, weasels, badgers, civet-cats, seals, and sea-bears, also belong to this group.

If you enter the small mammalia house you may see a beast allied to the badger and weasel, called the kinkajou. This animal is an inhabitant of Brazil, and its tail bears a relation to the region it inhabits.

The animal lives in trees which it roams over in search of small animals on which it preys, such as birds' eggs and bees' nests, and these nests its sharp strong claws can tear, while it has an extremely long tongue, capable of being thrust into the cells and extracting the honey. But its tail, which is very long, is specially modified to assist it in its mode of life. The end of the tail is curled round, and is capable of strongly grasping any object about which it may be twined.

This kind of tail is called a "prehensile tail," and acts as a fifth grasping organ, in addition to the two hands and the two feet.

It is in this prehensile character that the kinkajou's 
tail, as I said, bears a relation to the region it inhabits. For Brazil consists mainly of an enormously extended forest, South America presenting us with the main forest region of the world. Consequently, the animals inhabiting this region must be fitted for an exceptionally arboreal life. The primeval forest exhibits as it were a world borne aloft upon enormous pillars.

Walking in such a forest, one wanders in obscurity amongst enormous lofty trunks, at the summits of which is a mass of entangled foliage high over head, and shutting out almost completely the sun's rays from below. It is in this upper world that most of the forest animals live, and such conditions necessitate in them special modifications of structure, of one kind or another, and the prehensile character of the kinkajou's tail is one such modification. I do not mean to say that animals with prehensile tails are not found elsewhere; we shall shortly see that they are. Neither do I mean to say that this particular character is universal amongst forest-living beasts of South America. The sloths, for example, are notoriously and exclusively forest-dwellers, and they are most exceptionally modified to suit their dwelling-place; but the mode of modification by which they are suited to a forest home is of quite another kind; it is one, however, which it would be beside our purpose to enter upon to-day. Nevertheless, this particular character of tail does crop up amongst South American beasts remarkably. Thus, for example, let us consider the great order of monkeys. Monkeys are scattered over almost all the warmest parts of the earth save the West Indies, Madagascar, New Guinea, and Australia. A great variety of species are found in Africa, India, and the Indian Archipelago, and many of them have long tails; but not one kind of monkey in Asia or Africa. has a prehensile tail. In South America, however, we find apes (such as the Howling Monkeys and the Spider Monkeys) which have tails most perfectly prehensile, for they are naked beneath towards the tip, and on that account can be applied more closely and firmly to any object grasped more firmly by the tail than they could be grasped were the tail entirely hairy. The tail, indeed, is not only capable of alone supporting the weight of the body, but even of seizing a small movable object, and bringing it in as a hand would do to the mouth.

Monkeys may have long or they may have short tails, and there are some which have no visible tails at all. This is the case with the only European ape-the one which inhabits the Rock of Gibraltar. It is also the case

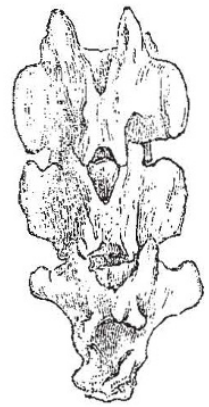

FIG. I.-Caudal verteb:æ of Iwnus.

with the Gibbons, or long-armed apes (which we have had living here from time to time, and some of which are so remarkable for their powers of voice). It is also the case with the orang-outang, the chimpanzee, and gorilla, which are as devoid of tails as we are. But are they, and are $z e$, really devoid of tails? Practically, of course, we are so, but nevertheless the spinal column has a rudimentary continuation formed of a few very imperfect vertebræ-not sufficiently elongated to form an external projection, so that in the human skeleton a minute tail is to be seen, though none is visible in the unmutilated adult body. In the earliest stages of our existence, however, there is for a short time a real tail of considerable relative extent, but in the development of the body it becomes stationary, so as rapidly to become altogether overshadowed and hidden.

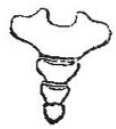

Fig. 2. - The Coccyx. At its upper end are the two prezygapophyses.

As I have said, Madagascar is not inhabited by monkeys, but it is inhabited, instead, by creatures called lemurs, with long fox-like muzzles, of which several are now living in our monkey-house. There also there was lately living another Madagascar creature (a near ally of the lemur) called Chierogaleus, and some of these creatures are said to present an interesting peculiarity in the tail.

Although Madagascar is a hot country, yet some of the animals inhabiting it fall into a profound sleep, or torpor, during the dry season, just as our own hedgehog falls into a profound torpor during the winter. Now some of these little lemur-like animals, called Cheirogalei, accumulate during a part of the year a great quantity of fat in the tail, which, in consequence, appears much swollen and enlarged. Upon this fat the animals appear to subsist during the other part of the year-not, of course, that they eat it, but that it becomes gradually absorbed, so that as the year comes round, the tail becomes as small again as it was when the fattening process began.

I have shown you how rudimentary the tail is in ourselves. There are many other animals, however, in which there is no tail. In certain bats the bones of the tail are firmly united at their hinder end with the bones of the hip-girdle or pelvis, so that at first sight there seems to be even less tail in them than in ourselves.

Very different is the condition of the tail in other bats, such as in all those which fly about in summer evenings: in England.

These creatures fly by means of wings which are hands with fingers enormously long and exceedingly slender, and tied together by skin, their hands being web-fingered as a duck's foot is web-toed. But not only does this skin extend between the long fingers, it also extends from the hands to the sides of the body and legs, forming an enormous membranous wing on each side of the body.

The tail is similarly conditioned. A membrane extends inwards from the whole length of the inside of each leg, and joins the adjacent side of the tail, which is thus held in a membrane called inter-femoral, from its situation. In the bat the tail serves as a rudder in flying, but it also performs another function, for by the bending forwards of the tail and the inter-femoral membrane it serves as a cradle in which the infant bat is held on its first appearance in the world.

An "inter-femoral membrane" extending from the legs. to the tail between them, also exists in an animal of a widely different form and nature, namely, in the seal.

The two hind legs of the seal are of no use whatever to the animal for progression on land, and the seal thus differs from the sea-bear. The hind-legs of the seal are kept extended out backwards, much in the position in which a man holds his legs when he swims. But they act in quite a different way in swimming from the way our legs act. Being united by an inter-femoral membrane with the tail, the whole mass of the legs and tail together form a sort of fin, which strikes the water as a whole, and so propels the body of the animal along in the water.

Very different is the tail of the whale, porpoise, or such a creature as the manatee or the dugong. None of these. creatures have hind-legs at all, or but the merest rudiment 
of such in the shape of a few very small bones buried in but in this expansion there are no limb-bones whatever ; the flesh. On the other hand, the tail is enormous in bulk, it is only a cutaneous expansion. This expansion extends and expands outwards on each side at its hinder end, horizontally in these animals. Why is this?

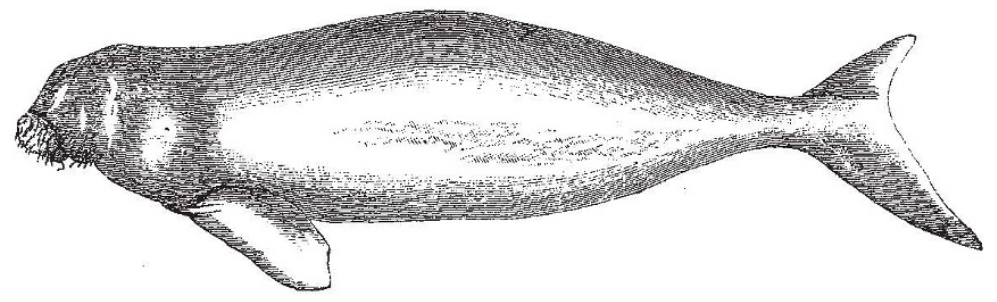

FIG. 3.-Dugong.

Fishes, such as the cod, perch, salmon, shark, \&c., have the ends of their tails expanded vertically, not horizontally, and it is very evident why.

Fishes swim by bending the tail from side to side and striking the water laterally, as those in any aquarium will show us. They also breathe by the water which flows over their gills.

Whales and porpoises are not fishes, but they are (as is also the manatee and the dugong) aquatic beasts, and they breathe air by lungs as other beasts do. This is the key to the difference in their tails, that is, the horizontal expansion of the hinder end. They require to bring their heads pretty often to the surface to breathe, and the horizontally expanded tail is well fitted to help them in so ascending by its downward blows.

But the tail of the whale or porpoise, strange to say, affords perhaps a partial explanation of the form of the head in these animals. For whales and porpoises are quite remarkable for the large size of their brains. Now the brain is commonly supposed-and in many cases with much reason-to be related to the powers of sensation and imagination which animals possess. Yet it is impossible to think that these marine creatures have any need for exceptionally acute or powerful minds.

But brain stuff is known to be related to motion, no less than to feeling and imagination. Unless our muscles were duly stimulated by nerves and by the brain and spinal cord, they would not act. It may well be then that these animals need all their brains to supply enough nerrous energy for the incessant muscular exertion which their habit of life renders necessary in the medium they inhabit. But this explanation alone will not do, for fishes have very small brains. The difference is perhaps due to the fact that whales and porpoises need to maintain a high body temperature, while fishes are cold-blooded and brain stuff is needed to maintain bodily heat no less than for sensation and motion.

The tails of beasts are generally like their bodies, covered with hair. The rat and mouse and certain opossums offer exceptions in their naked, scaly looking tails.

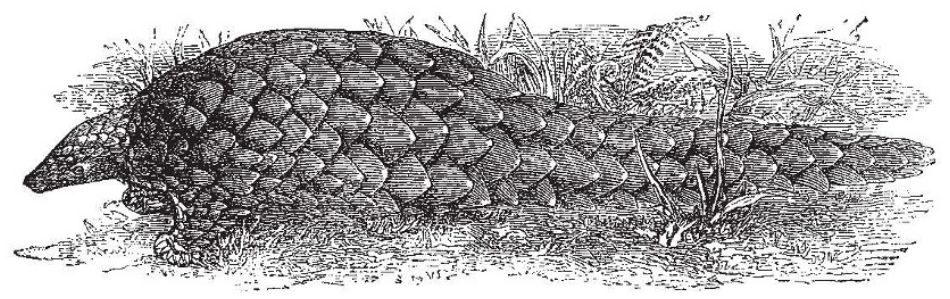

FIG. 4.-The Pangolin (Nanis).

One animal from Africa, a creature much like a flying squirrel (Anomalurus) presents (as its name implies) a very exceptional condition of tail. It is really scaly in part, for underneath it, at a little distance from its root, it is furnished with horny overlapping scales. Such scales are yet more developed in another beast-the manis or pangolin-but then in this latter animal the whole body and limbs are thus invested and not part of the tail only.

The animal renowned for its curious naked tailflattened out like a trowel-is the beaver. As to the use of this animal's tail our experienced superintendent, Mr. Bartlett (who is so acute and accurate an observer of animals' habits) assures me that he has often watched beavers when at work building with mud in snow, but in no instance has he seen them make use of the tail as a trowel as has so often been alleged. But the beaver has great power in its tail, not only as are organ used in swimming but as a means of sounding an alarm to its comrades. On the approach of an enemy the beaver strikes the surface of the water with its flat tail with such force that it can be heard, on a still night, half a mile off. Upon hearing this signal all the beavers in the neighbourhood quickly dive under the water.

The beavers which still linger in European rivers have now ceased to construct dams as do their American fellows. It is an interesting fact, however, that they still retained this habit in Europe down to the time of Albertus Magnus, who of course knew nothing of the habits of the beavers of the then undiscovered America.

In the Zoological Gardens are creatures which are provided with exceptionally powerful tails - for land animalsI mean the kangaroos. These creatures make use of their tails not only sometimes to carry grass, and to a certain extent in their long jumps, but constantly when sitting with the fore part of the body raised, and in this position they often raise themselves high up on their extended hind legs and on their tail as on a strong tripod, at which time they have a most comic appearance.

And this brings me to speak of another matter. As I have said the sloths are fitted to live in trees not by any peculiar development of tail, but in other ways. Certain gigantic extinct allies of sloths, however, were fitted for a forest life and to live entirely on the foliage of trees by their tails. Such extinct beasts were the Mylodon and Megatherium, creatures equalling or exceeding the rhinoceros in bulk.

The modification of tail specially adapted for forest life with which we have as yet met, has been a prehensile tail. This we have seen in the kinkajou and in howling and spider monkeys, Many other beasts, how- 
ever, of very different kinds are provided with prehensile tails.

Amongst others may be mentioned tree-porcupines, certain opossums, and a small ant-eater. All these animals live on trees. But the mylodon and megatherium -though forest animals living in all probability exclusively on the foliage of trees, were far too bulky to climb them, or to be supported by their branches. They appear to have fed thus: raising themselves on their hind legs and tail (as on a tripod-like the kangaroos) they embraced trees with their powerful arms, and swaying them to and fro, gradually prostrated them in order to feed upon their leaves. It has been objected to this view of their probable habits, that if they acted in this way they must often get their heads broken. Well, strange to say, the heads of some fossils have had their heads broken and healed again, and their skull was specially constructed so as to obviate to a considerable extent the danger of fatal consequences ensuing from accidents of that kind.

The tails of some beasts are, as I have said, exception. ally naked. The tails of others, however, are exceptionally hairy. Such is the case with the horse, which is called "long-tailed" when the tail is adorned with a clothing of very long hairs.

(To be continued.)

\section{OUR ASTRONOMICAL COLUMN}

IBELA'S COMET IN I852.- - In view of the probable approach to the earth's orbit of the two heads of Biela's comet in the present year, it is not without interest to recall the circumstances under which these bodies were last observed in the autumn of 1852 . As soon as the calculated place of what was assumed to be the principal comet of 1846 , according to Santini, was sufficiently removed from the sun's place to afford a chance of discovery, a search was commenced at several European observatories, notably by Secchi, at the Observatory of the Collegio Romano at Rome. The comet was not found in its computed position, and the cause of this is now known to have been the abandonment by Santini of his old semi-axis major, founded originally upon Damoiseau's calculation of the perturbations of mean motion between the appearances in $1805-6$ and 1826 , and the observations of those years and the substitution of a value deduced by Plantamour from the observations in $1845-46$; had the original semi-axis been retained the comet would have been readily found by means of Santini's computations. Extending the limits of the search, therefore, Secchi detected a faint comet on the morning of August 26 , 1852 , some $6^{\circ}$ from the calculated place, which Prof. Peters of Altona immediately pointed out as probably one portion of Biela's comet, from the rate and direction of its motion, as, indeed, it proved to be. (In Memorie dell Osservatorio del Collegio Romano, anni $1852-55$, the discovery is dated, by a misprint, August 16 , civil reckoning, the first observation was made on August 25, at I6h. I4m. M.T.) This object was observed on several subsequent mornings, and on September 16 Secchi found the other head of the comet, following that previously observed about two minutes of time, and about half a degree to the south. With the great refractor at Pulkowa, M. Otto Struve found Secchi's comet of August 26, on September I8 (astronomical), or immediately after the notice reached him, and two mornings later, he observed both heads. Mr. James Breen, to whom Prof. Challis had intrusted the Northumberland equatorial at Cambridge for a search for the comet, found one portion of it on September 8, and observed it further on September 16 and $2 \mathrm{I}$. At Berlin one head was detected on September 17 , and reobserved on September 22. M. Otto Struve, in his account of the Pulkowa observations, calls that head of the comet which was first observed by Secchi on August 25, $A$, and that found on September 15 , using now astronomical dates, he calls $B$; the latter was the north. preceding comet, the former the south-following one. A discussion of the observations of both heads, twenty-two in number, showed that those at Cambridge referred to $\mathrm{A}$ on all three mornings, and those at Berlin to B; both nuclei were observed at Rome on September I9 and 20, and at Pulkowa on September 20, 23, and 25. The appearance of the two portions of the comet is best described in M. Otto Struve's memoir, which is also accompanied by two admirably executed drawings, depicting their relative aspect on September 20 and 25 , $\mathrm{B}$ on September I8 was at least $30^{\prime \prime}$ in diameter, with sensible brightening in the centre, but no decided nucleus, and the light of the comet was about equal to that of a star of Argelander's ninth magnitude. On September 20 A was easily seen with the finder of the large refractor, both heads were of about equal brightness, $B$ might be a little the brighter, and exhibited a distinct nucleus; the nucleus of $A$ was not so distinct as that of $B$, and there was a greater brightness of the nebulosity, as well as an extension of it in the direction of $\mathrm{B}$; the apparent diameters about $\mathrm{I}^{\prime}$ and $4 \mathrm{O}^{\prime \prime}$; the diameter of $\mathrm{B}$, which was circular, was estimated $40^{\prime \prime}$. On September $23 \mathrm{~A}$ was notably fainter than $B$, and without nucleus; the lengthened form of A was only seen with difficulty, but the sky was not quite transparent. On September 25 there was a remarkable change as compared with the relative appearance of the two heads five days before; A was materially fainter than $B$; the latter was very distinct in the finder, while the place of the former was hardly suspected; diameter of $\mathrm{A}$ about $30^{\prime \prime}$, that of $\mathrm{B}$ from $50^{\prime \prime}$ to $60^{\prime \prime}$. A was round, B slightly oblong; the brightest part of A was not in the centre of the nebulosity, but in the direction of $B$, and the nucleus of $B$ was in the opposite direction to $A$, the brightest part of the nebulosity unequally distributed about the nucleus of $B$ being turned away from $A$; the position-angle of this direction was $286^{\circ}$. On September 28 , the last day of observation, the moonlight was strong, and $B$ only was seen with difficulty. We give these details, not remembering to have seen them reproduced in this country; but the description fails to convey the impression made by comparing M. Otto Struve's drawings of September 20 and 25 ; were it not that we know to the contrary, it might almost be inferred therefrom that one portion of the comet had revolved round the other to the extent of $180^{\circ}$; their relative appearance had been wholly interchanged, and it will be remembered that about February 12, I846, the secondary comet much exceeded in brightness the primary one, though this continued only three or four days, when the latter resumed its previous decided superiority. There was thus, as $M$. Struve remarks, the same interchange of brightness between the two nuclei at both appearances, and this he is inclined to attribute to a mutual action. It may, how. ever, be remarked that the distance between them in 1852 was, according to Hubbard, 0.0193, or about $1,750,000$ miles, which seems to militate against such an explanation, and rather to induce an idea of action inherent in the separate comets, or of influence exercised upon them through their approach to the sun. At M. Struve's observations of September 20, using Hubburd's elements, we find the distance of $\mathrm{A}$ from the earth was I 492 , and that of $\mathrm{B}, \mathrm{x} 483$; while on September 25 , the distance of $\mathrm{A}$ was $\mathrm{I}^{\circ} 525$, and of $\mathrm{B}, \mathrm{I} \cdot 5 \mathrm{I} \mathrm{I}$; so that there was no marked change of distance between the dates of his drawings.

VARIABLE STARS. - The following are Greenwich mean times of geocentric minima of Algol observable in this country during the last three months of the present year:-

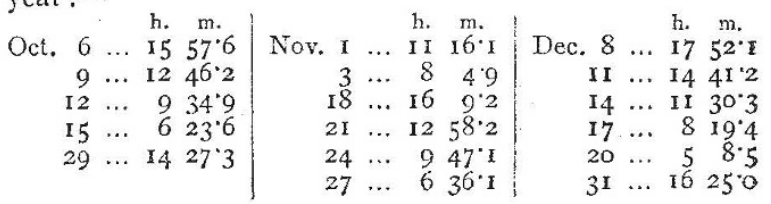

